\title{
Brain Stem Signs in Acute Cervical Cord Trauma *
}

\author{
J. Irwin, R. J. Abbott, A. A. Burt, and D. Harriman \\ Regional Spinal Injuries Centre. Pinderfields General Hospital, Wakefield E Dept \\ of Neuropathology, Leeds General Infirmary, Leeds, UK.
}

\begin{abstract}
Summary
Four cases are reported which illustrate mechanisms by which patients with cervical cord trauma may develop signs of acute brain stem damage. Two patients suffered vertebro-basilar ischaemia as a result of trauma to the vertebral arteries. The remaining two patients developed cavitating lesions within the cervical cord which later dissected rostrally into the brain stem.
\end{abstract}

Key Words: Spinal Cord Injury; Syringomyelia; Syringobulbia; Brain Stem Signs.

\section{Introduction}

Patients who receive severe trauma to the neck may sustain irreversible damage to the spinal cord which renders them tetraplegic. The neurological deficit does not usually extend above the neck, but occasionally patients are seen who subsequently develop clinical features which are indicative of brain stem involvement. We describe four patients in whom two separate mechanisms for brain stem damage are evident, namely 1) Vascular injury and 2) Upward dissection of acute cord cavitation.

\section{Vascular injury}

The vertebral artery can be damaged by vertebral injury and this usually occurs at one of three sites (Simeone and Lyness, 1976). 1) At the entry of the artery into the foramen transversarium of the sixth cervical vertebra, 2) as it swings over the arch of the atlas and 3) opposite the fracture site, usually at the level of the disc space.

We present two such patients with vertebrobasilar ischaemia.

Patient 1. A 47-year-old male was immediately rendered tetraplegic when

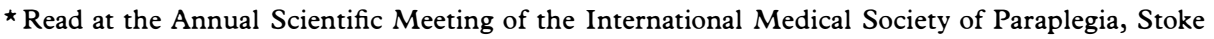
Mandeville Hospital, Aylesbury, Bucks, England, May 1983. 
a heavy fire door fell on to his head whilst he was unloading a lorry. The incident caused forcible flexion of his cervical spine. On examination he had a complete C4 tetraplegia and X-rays showed a fracture dislocation of C4 on C5.

Seven hours after admission he developed a transient bradycardia of 36 beats per minute. At 12 hours he suddenly lost consciousness associated with further bradycardia. On regaining consciousness he was found to have paralysis of conjugate gaze to the right and bilateral nystagmus. Three hours later he again lost consciousness and subsequently died.

Post mortem examination revealed a recent thrombus in the basilar artery which had extended from a vertebral artery thrombosis at the level of the injury.

Patient 2. A 50-year-old male fell from a lorry sustaining a neck injury. On assessment at the Spinal Injury Unit 5 hours later he had full power at the wrists and above. Finger flexion was grade 3 bilaterally, but he had no other finger movement. All muscle groups in the legs had grade 1 power. Dorsal column sensation was intact but he was anaesthetic below $\mathrm{T} 1$.

Plain radiographs of the cervical spine were normal but the CT Scan (Fig. 1) showed a fracture extending through the right foramen transversarium of the sixth cervical vertebra.

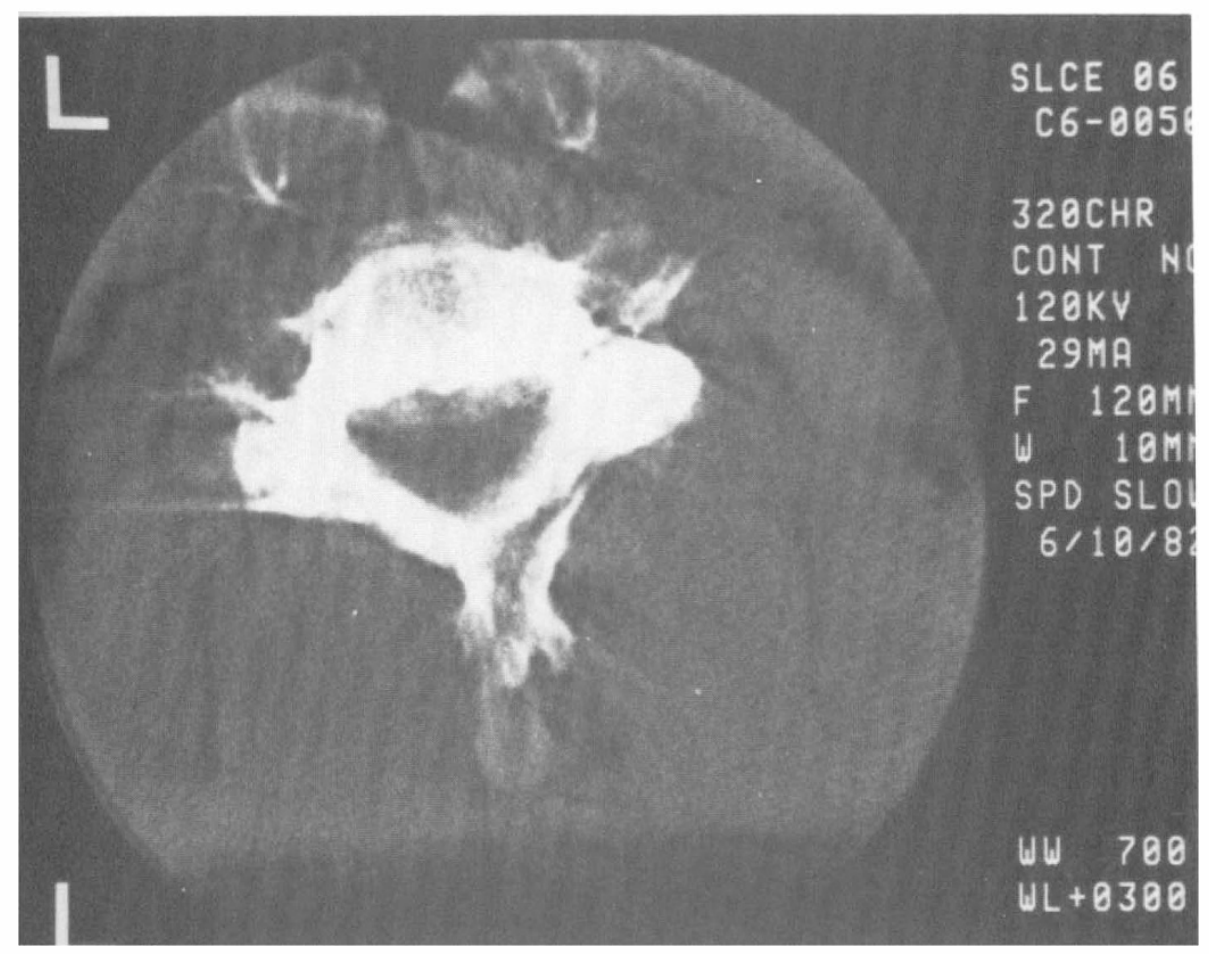

Figure 1. CT Scan from Patient 2 showing a fracture extending through the right foramen transversarium of the sixth cervical vertebra.

By 4 weeks he had regained full sensation and muscle power was returning. Attempted mobilisation at 6 weeks was prevented by symptoms of severe 
vertebro-basilar insufficiency. Every time he sat up he developed severe vertigo, nystagmus and frequently lost consciousness.

Vertebral angiography (Fig. 2) revealed complete occlusion of a hypoplastic right vertebral artery at the level of the fracture which had been demonstrated by the CT Scan.

His symptoms gradually improved and had resolved completely 4 months after the injury.

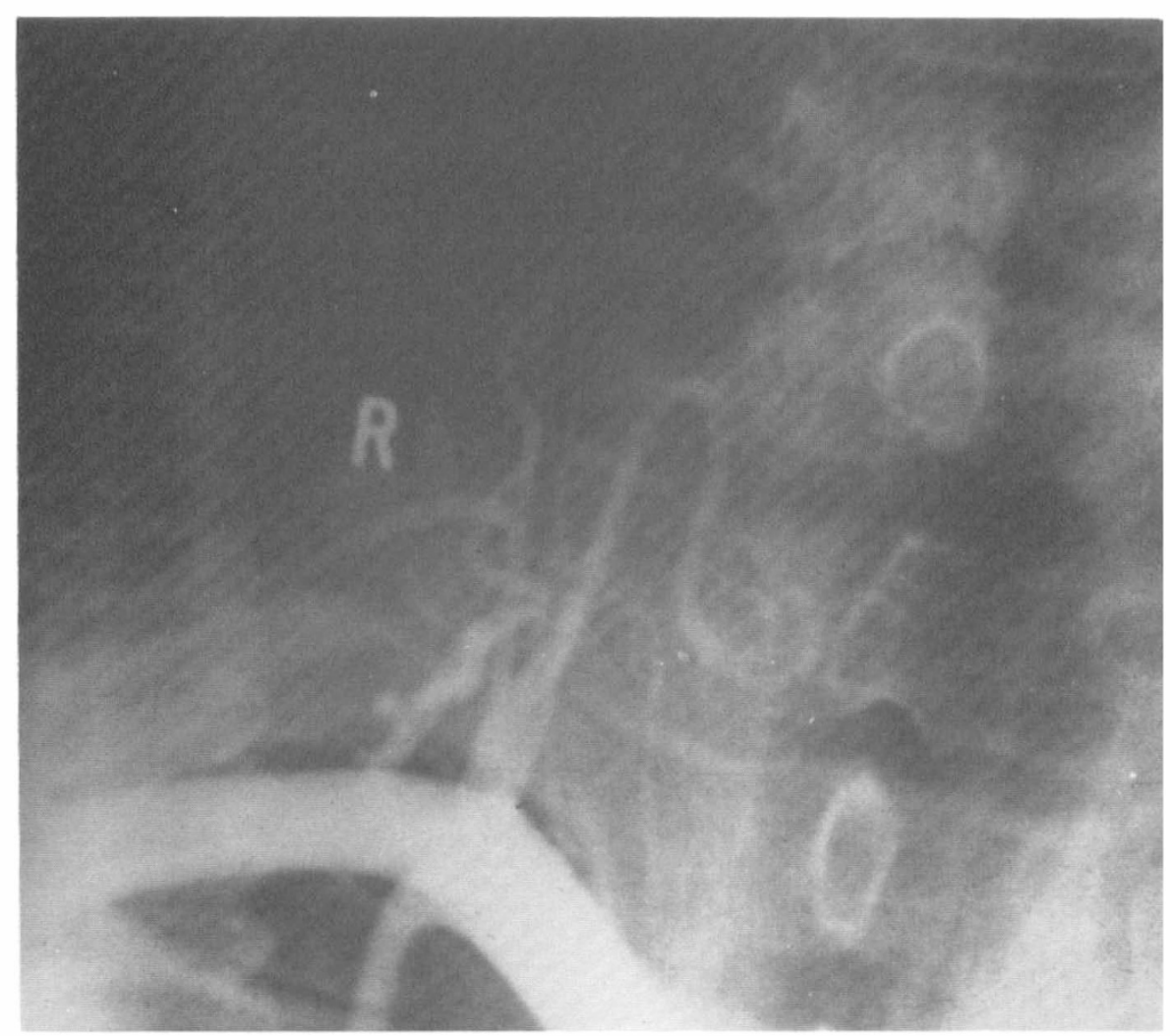

Figure 2. Vertebral angiogram from Patient 2 shows complete occlusion of a hypoplastic right vertebral artery at the level of the fracture which had been demonstrated on the CT Scan.

\section{Upward dissection of acute cord cavitation}

It is well known that spinal cord injury can cause an acute myelomalacic cavity which is usually situated centrally or dorso-laterally. (Barnett and Jousse, 1976; Shannon et al., 1981; Williams et al., 1981.) Patient 3 developed brain stem signs following cephalad dissection of 'such a cavity'.

Patient 3. Whilst drunk on his 21 st birthday he dived into the sea and was immediately rendered tetraplegic at C6 level. Plain radiographs showed a burst fracture of C5, and a CT Scan confirmed the disruption of anatomy at this site.

Eight days after the injury he developed tingling of the lower face bilaterally, without objective sensory loss. The next day he reported that he could no longer 
move his shoulders or flex his elbows, and 12 hours later he had a respiratory arrest. He was intubated and ventilated and at this stage had fixed dilated pupils, paralysis of conjugate gaze bilaterally and impaired sensation to pin prick in the lower two divisions of both trigeminal nerves.

Eight days later he was successfully weaned from the ventilator and

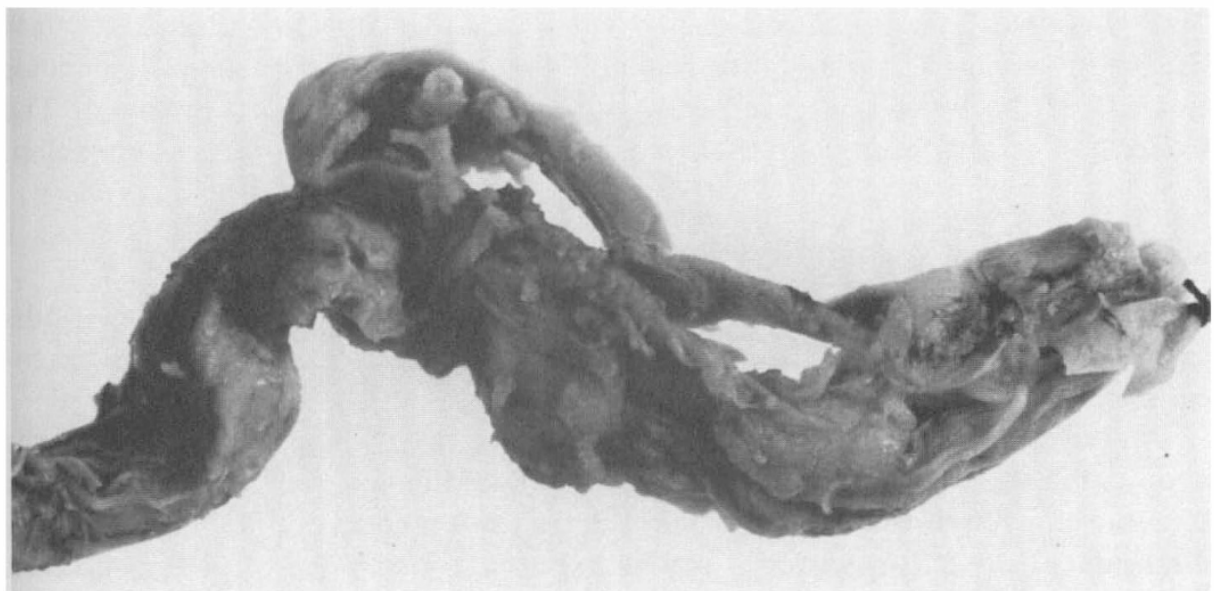

Figure 3. Post mortem specimen from Patient 3. At C4 to C5 the cord is splayed open creating an artificial syrinx.

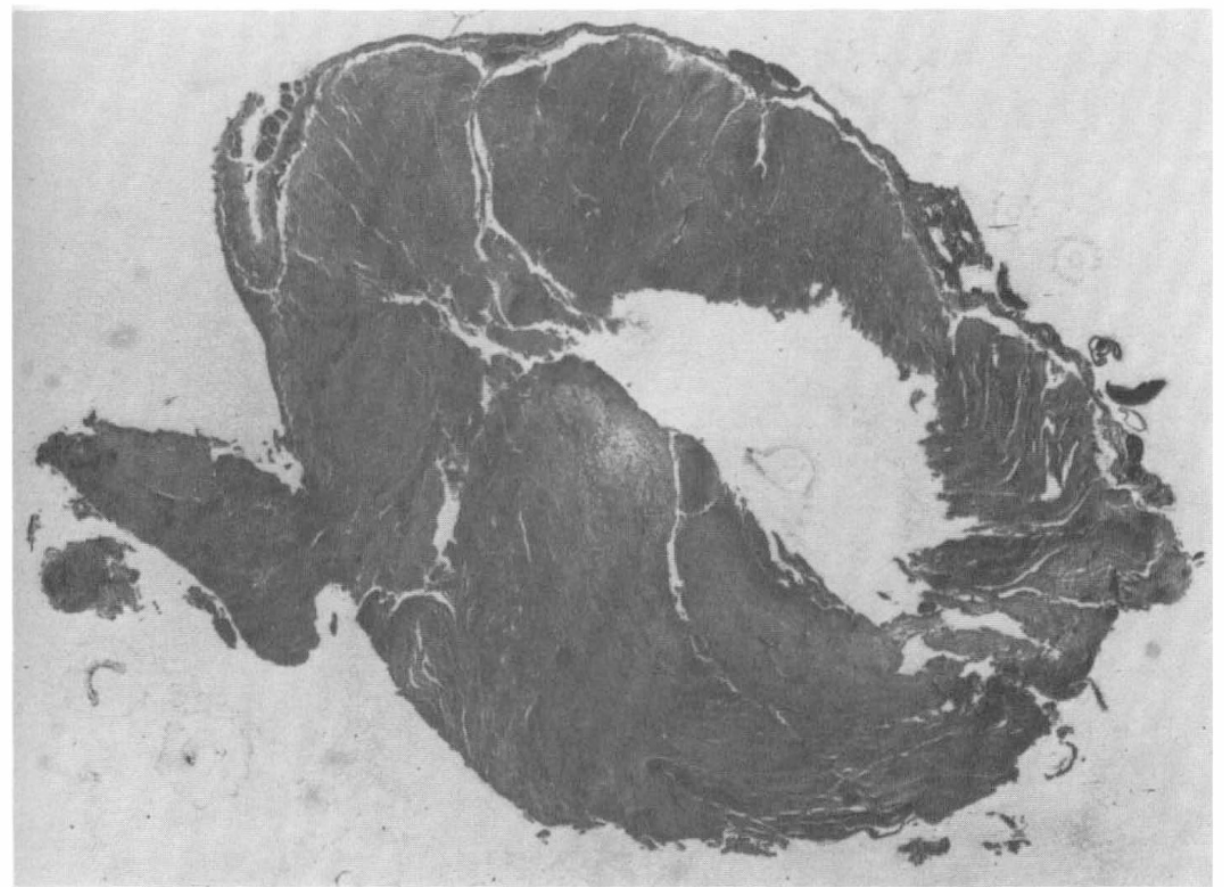

Figure 4. Transverse sections of the cervical cord from Patient 3 shows a myelomalacic cavity which extended unilaterally into the medulla. 
examination revealed bilateral ptosis, bilateral facial weakness, complete ophthalmoplegia and impaired lip and tongue movements. After a further 5 days he could move his eyes but had ataxic nystagmus.

Unfortunately he succumbed to an overwhelming chest infection 13 months after his injury.

Post mortem examination of the medulla and upper cervical cord showed splaying of the cord at C4-5 level with a cavity (Fig. 3). Above and below this level there was a myelomalacic cavity which extended upwards unilaterally into the medulla (Fig. 4) ending in the region of the twelfth nerve nucleus. The motor nucleus of the tenth nerve and the vestibular nuclei were also involved. The cavity had no glial lining and there was no evidence of haemosiderin deposition.

\section{Post traumatic syringomyelia with syringobulbia}

Post-traumatic syringomyelia is well recognised (Williams et al., 1981, Griffiths and McCormick 1981; Watson 1981; Rossier et al., 1981). However, syringobulbia as was seen in patient 4 is less common.

Patient 4. A 45-year-old miner presented 5 weeks after being hit on the shoulders by an iron bar. He initially complained of shoulder pain but one week later developed numbness at the back of the neck, weakness of the shoulder girdle, weakness of the left quadriceps and had spontaneous clonus of the right ankle.

On examination he had a left Horner's syndrome and rotatory nystagmus. His head was held tilted to the left. There was impaired sensation to pin prick in the third and fourth cervical dermatomes bilaterally and also in the second

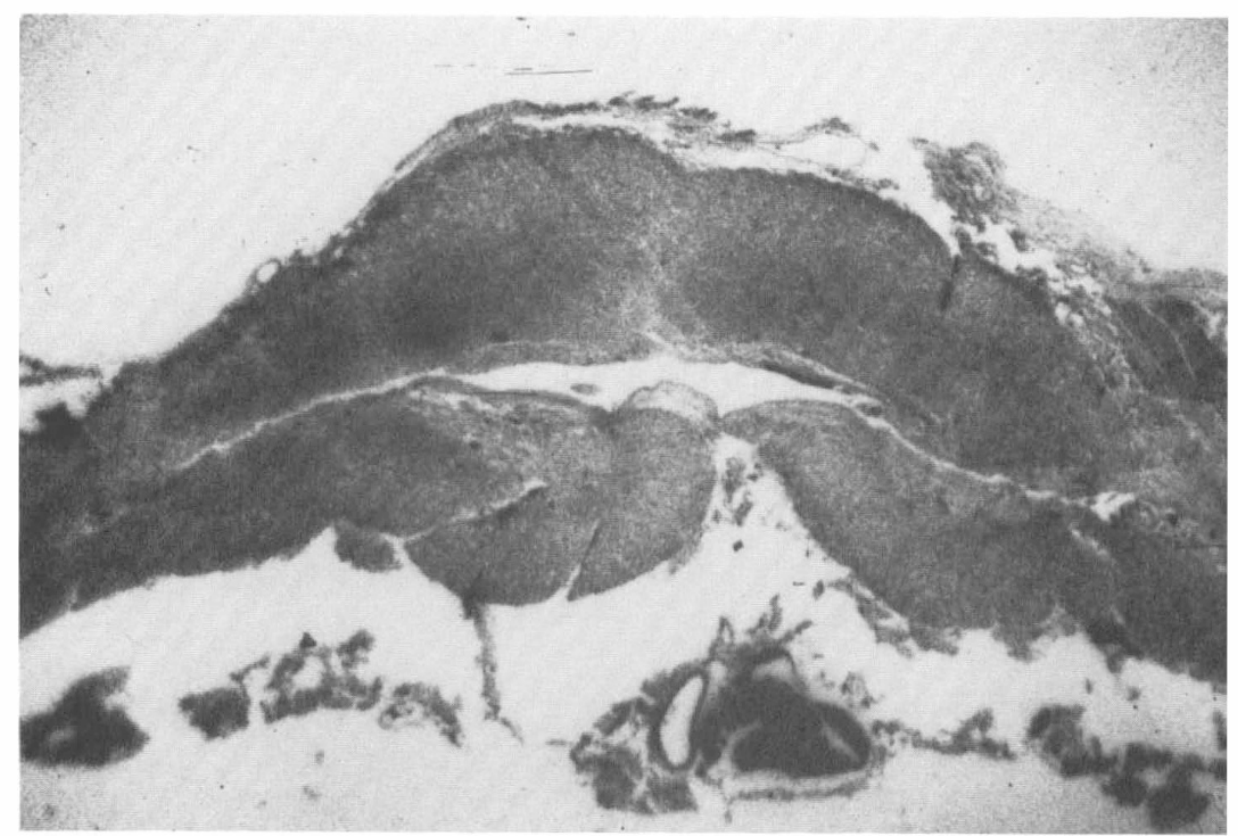

Figure 5. Transverse section of cervical cord from Patient 4 showing a syrinx which extended from $\mathrm{C} 3$ into the medulla oblongata. 
cervical dermatome on the right. Temperature sensation was impaired in both hands and forearms with a recent cigarette burn of the left hand.

There was wasting of the supra-clavicular muscles bilaterally and weakness of the right serratus anterior, right hip flexors and left quadriceps. Spasticity and hyperreflexia were present in all limbs.

A diagnosis of syringomyelia with syringobulbia was made. Plain radiographs showed spondylosis but no fracture. Myelography showed no evidence of cerebellar tonsillar ectopia.

He died aged 56 years from cor pulmonale.

At post mortem there was a central cyst (Fig. 5) extending from the medulla to C3 and from C4 to T8. At the level of C3-4 the cyst lay in very close approximation with the arachnoid and may have communicated with the subarachnoid space. The cyst had a glial lining and communicated at the upper end with the fourth ventricle. An area of gliosis was evident posterolaterally in the medulla and upper cord which communicated with the cavity at C1 level. This gliosis probably represented an area of direct traumatic damage.

\section{Discussion}

The development of brain stem signs in acute spinal cord injury is unusual. All four of our patients had unequivocal clinical, and in three cases pathological, evidence of brain stem damage. Patients 1 and 2 had vertebro-basilar ischaemia due to injury to the vertebral arteries in the vertebral canal. Similar patterns of vascular injury have been described, even with minor manipulative operations of the cervical spine.

Patients 3 and 4 presented with bulbar signs at 8 days and 5 weeks respectively following cervical cord trauma. Post mortem examinations were subsequently performed in both patients, the former being shown to have a myelomalacic cavity extending into the medulla, and the latter a syrinx which communicated with the 4 th ventricle. The mean interval from trauma to the onset of progressive symptoms due to a syrinx was 12 years in a previous report (McComas et al., 1983), although Jensen and Reske-Nielson (1977) described the onset of symptoms in one patient at 2 months. There is only one previous report of death as a direct result of this brain stem pathology (Oakley et al., 1981).

Several theories have been advanced as to the aetiology of post-traumatic syringomyelia. It is generally believed that cavitation precedes cyst formation, the cavity being formed due to either liquefaction of a haematomyelia, focal infarction relating to vascular trauma or lysosomal digestion of necrosed tissue (Williams et al., 1981). The spinal cavitation in Patient 4 showed no evidence of haemosiderin deposition at post mortem and was probably not, therefore, secondary to haematomyelia. It may well have formed as a result of infarction at the site of trauma and later dissected rostrally into the medulla. The mechanism for this dissection 8 days after injury is unknown, but the cause of death was probably concentric oedema involving the respiratory centres in the medulla.

Patient 4 represents only the fifth patient in the literature in whom posttraumatic syringobulbia has been confirmed at post mortem. Brain stem signs were first noted 5 weeks after his injury and it is probable that the syrinx had extended into the medulla even at this early stage. At post mortem there was 
no evidence of a pre-existing anomaly at the level of the foramen magnum and the cyst communicated with the 4 th ventricle. A communication of this type has only been described once previously in a patient with post-traumatic syringomyelia. Our patient developed signs of syringobulbia extremely soon after the trauma, and the mechanism for the development of a syrinx at this early stage is unclear.

It may be that the mechanism by which this occurred was different from that which produces a syrinx many years after the initial injury. On the other hand our patient may represent a very early stage in the development of a condition which usually presents at a much later stage.

\section{Résumé}

On rapporte quatre cas qui montrent les mécanismes par lesquels les malades qui souffrent du traumatisme de la moëlle cervicale peuvent développer des signes de l'endommagement aigu du tronc cérébral. Deux de ces malades ont éprouvé l'ischémie vertébro-basilaire par suite d'un traumatisme qui touchait les artères vertébrales. Les deux autres malades ont développé des lésions cavitantes à l'intérieur de la moëlle cervicale qui se sont disséquées plus tard dans le tronc cécébral.

\section{Zusammenfassung}

Man berichtet vier Fälle, die die Mechanismen zeigen, wodurch Patienten mit Halsmarktraumatismus Zeichen von akuter Hirnstammverletzung entwickeln können. Zwei von diesen Patienten haben Wirbelbasilarischämie zu Folge eines Wirbelschlagadertraumatismus gelitten. Die zwei anderen Patienten haben kavernenbildende Läsionen innerhalb des Halsmarks entwickelt, die sich später rostral bis in den Hirnstamm zerschnitten haben.

\section{References}

Barnett HJH, Jousse AT 1976 Post-traumatic syringomyelia. In: Vinken PJ, Bruyn EM (eds) Handbook of Clinical Neurology. Vol. 26, 113. North Holland Publishing Co., Amsterdam.

Griffiths ER, McCoRMICK CC 1981 Post-traumatic syringomyelia (cystic myelopathy). Paraplegia 19:81-88.

Oakley JC, George MD, Ojemann MD, Alvord Jr EC 1981. Post-traumatic syringomyeliaa case report. Journal of Neurosurgery 5:276-281.

Rossier AB, Foo D, Shillito J, Naheedy MH, Sweet WH, Dyro FM, Sarkarti M 1981 Progressive late post-traumatic syringomyelia. Paraplegia 19:96-97.

Shannon N, Symon L, Logue V, Cull D, Kang J, Kendall B 1981 Clinical features, investigation and treatment of post-traumatic syringomyelia. Journal of Neurology, Neurosurgery and Psychiatry 44:35-42.

SiMEONE FA, LYNESS SS 1976 Vertebral artery thrombosis in injuries of the spine. In: Vinken PJ, Bruyn EM (eds) Handbook of Clinical Neurology. Vol. 26. 57. North Holland Publishing Co., Amsterdam.

Watson N 1981 Ascending cystic degeneration of the cord after spinal cord injury. Paraplegia 19:89-95.

Williams B, Terry AF, Jones HWF, McSweeney T 1981 Syringomyelia as a sequel to traumatic paraplegia. Paraplegia 19:67-80.

McComas CF, FROST JL, SCHOCHET SS 1983 Post-traumatic syringomyelia with paroxysmal episodes of unconsciousness. Archives of Neurology 40:3220324.

JenSEN F, RESKE-Nielson E 1977 Post-traumatic syringomyelia. Scandinavian Journal of Rehabilitation Medicine. 9:35-43. 